
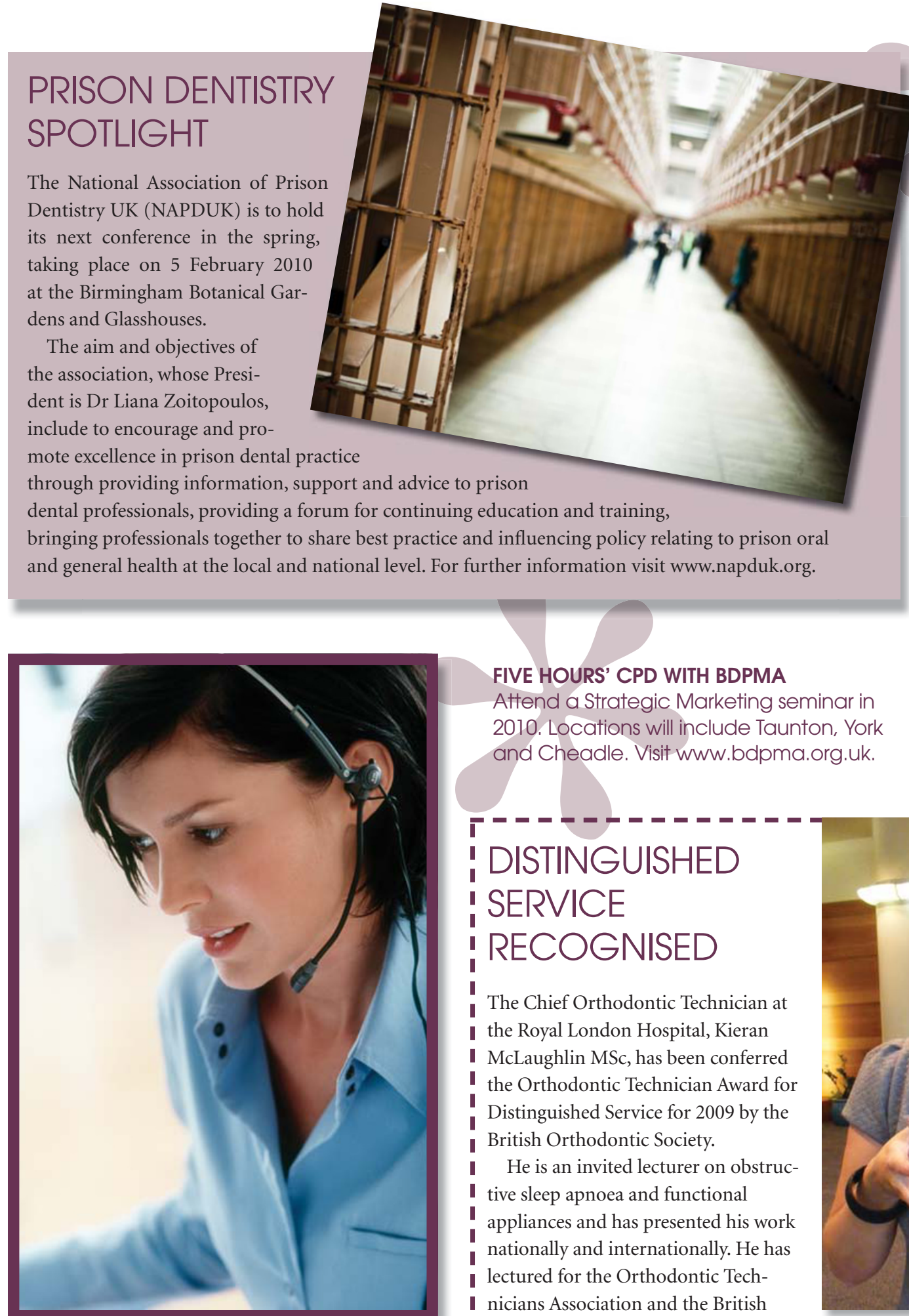

\section{NHS DIRECT CALLS FOR DENTAL NURSES}

A new career opportunity has opened up for qualified dental nurses at NHS Direct as it expands its team to answer the growing number of dental enquiries the service receives. Dental nurse advisors now work as part of NHS Direct's front-line team, speaking directly to patients and providing dental information and advice from one of NHS Direct's 35 contact centres across England. For more information and to apply for dental nurse vacancies at NHS Direct visit the website at www. nhsdirect.nhs.uk/dental.

\section{FIVE HOURS' CPD WITH BDPMA}

Attend a Strategic Marketing seminar in 2010. Locations will include Taunton, York and Cheadle. Visit www.bdpma.org.uk.
T

DISTINGUISHED ISERVICE RECOGNISED I

The Chief Orthodontic Technician at I the Royal London Hospital, Kieran

I McLaughlin MSc, has been conferred

I the Orthodontic Technician Award for

Distinguished Service for 2009 by the British Orthodontic Society.

I He is an invited lecturer on obstrucI tive sleep apnoea and functional

appliances and has presented his work

nationally and internationally. He has

lectured for the Orthodontic Tech-

I nicians Association and the British

I Dental Association and has presented

his research at the International Associa-

tion of Dental Research conferences in

Ingapore and San Francisco.

I Kieran has also taught all aspects

of orthodontic appliance design and

construction to undergraduate and

postgraduate dental students as well as

I student dental technicians at Barts and

I the London School of Medicine and

Dentistry for more than 20 years, and has

almost 30 years of experience in ortho-

I dontic technology.

I This year the BOS Distinguished Serv-

I ice Award for an Orthodontic Dental
INDUCTION PACK FOR NEW DENTAL NURSES

Barnfield College Luton has won a special Knowledge Transfer award for a new dental nursing project. The project involved developing a standardised induction pack for new dental nurses.

The pack, which includes a special learner guide, provides guidance for the new employee and the dental practice and prepares the dental nurse for undertaking a GDCrecognised qualification leading to registration.

The award from the New Engineering Foundation was presented to Angie McBain, Barnfield's Lead Dental Nurse Tutor, by Paul Froggat of the Department for Business, Innovation and Skills at a special ceremony in London.

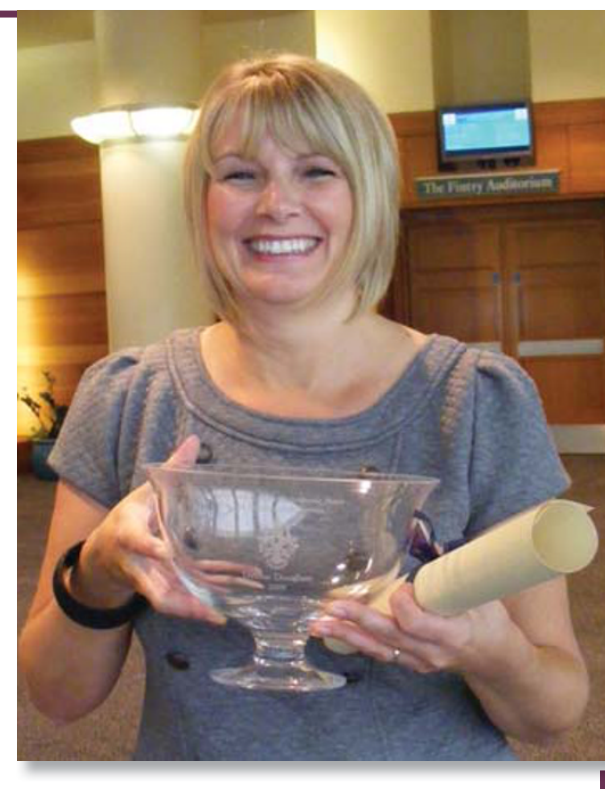

Nurse was presented to Denise Doug-

lass. An experienced orthodontic nurse,

Denise began her working life in the

Community Dental Service before

becoming the first dental nurse to be employed at the Cumberland Infirmary in Carlisle, where she is currently the Senior Dental Nurse. She extends her role by mentoring and training other dental nurses. Denise was the one of the founding members of the Orthodontic National Group for Dental Nurses (ONG) and was its first Membership sec- I retary and later its first Finance Officer. 